\title{
Cyclin B2/cyclin-dependent kinase1 dissociation precedes CDK1 Thr-161 dephosphorylation upon M-phase promoting factor inactivation in Xenopus laevis cell-free extract
}

\author{
FRANCK CHESNEL, FRANCK BAZILE, AUDE PASCAL and JACEK Z. KUBIAK* \\ Institute of Genetics \& Development, CNRS-UMR 6061, Mitosis and Meiosis Group, IFR140 GFAS, University of Rennes 1, \\ Faculty of Medicine, Rennes, France
}

\begin{abstract}
Cyclin-dependent kinase 1 (CDK1) is the enzymatic subunit of M-phase Promoting Factor (MPF). It is positively regulated by phosphorylation on Thr-161 and association with a cyclin $B$ molecule. The role of Thr-161 dephosphorylation upon MPF inactivation remains unclear; nevertheless, degradation of cyclin B is thought to be a direct cause of MPF inactivation. However, MPF inactivation actually precedes cyclin B degradation in Xenopus cell-free extracts. Here we study in details the temporal relationship between histone $\mathrm{H1}$ kinase (reflecting MPF activity) inactivation, Thr-161 dephosphorylation, CDK1-cyclin B2 dissociation and cyclin B2 proteolysis in such extracts. We show an asynchrony between inactivation of histone $\mathrm{H} 1 \mathrm{kinase}$ and degradation of cyclin B2. CDK1 dephosphorylation on Thr 161 is an even later event than cyclin B2 degradation, reinforcing the hypothesis that cyclin B dissociation from CDK1 is the key event inactivating MPF. Cyclins synthesized along with MPF inactivation could deliver shortly living active MPF molecules, potentially increasing the asynchrony between histone $\mathrm{H} 1$ kinase inactivation and cyclin B2 degradation. We confirm this by showing that in the absence of protein synthesis, such a tendency is lower, but nevertheless, still detectable. Finally, to characterise better CDK1/cyclin B dissociation, we show that CDK1 begins to dissociate from cyclin $B 2$ before the very beginning of cyclin B2 degradation and that the diminution in CDK1-associated cyclin B2 is faster than the decline of its total pool. Thus, neither cyclin B2 degradation nor Thr-161 dephosphorylation participates directly in CDK1 inactivation as measured by histone $\mathrm{H} 1$ kinase decline upon the exit from mitotic M-phase in Xenopus embryo extract.
\end{abstract}

KEY WORDS: cell cycle, histone H1 kinase, mitosis, protein phosphorylation/dephosphorylation, Thr-161

\section{Introduction}

M-phase Promoting Factor (MPF) is a universal mitotic regulator. It is composed of the enzymatic subunit - CDK1 (CyclinDependent Kinase 1) and the regulatory subunit - cyclin B. MPF activation triggers both mitotic and meiotic M-phase, while its inactivation results in mitotic or meiotic exit. For long time MPF inactivation upon the exit from meiosis or mitosis was thought to be provoked by cyclin B degradation via ubiquitin-proteasome pathway since the two phenomena are temporarily tightly linked (Murray et al., 1989; Glotzer et al., 1991). The proteolysis of mitotic cyclins is coordinated by Anaphase Promoting Complex/ Cyclosome (APC/C; Peters, 2002) which has an activity of ubiquitin ligase (Ciechanover, 2005; Hershko, 2005). It polyubiquitinates substrates and targets them to $26 \mathrm{~S}$ proteasome for degradation.

Cyclin B2 is one of the two major B-type cyclins expressed in
Xenopus laevis oocytes and early embryos. Upon oocyte activation or in calcium-treated CSF extract made of such oocytes all cyclins $B$ are degraded very fast (up to 10 min post-activation). Cyclins B1 and B4 disappear first and B2 and B5 are degraded slightly later (Hochegger et al., 2001). Cyclin B5 seem to be much less abundant than cyclin B2 (ibid.). B2 cyclin is therefore the latest major cyclin $\mathrm{B}$ degraded upon $\mathrm{M}$-phase exit in Xenopus oocytes. The same sequence of cyclins $B$ degradation is observed upon mitotic exit in cell free embryo extracts (Hochegger et al., 2001, Chesnel et al., 2005; 2006). The association of cyclin B2 with CDK1 is accompanied by its rapid phosphorylation on multiple N-terminal residues (Meijer et al., 1989; Gautier and Maller, 1991; Izumi and Maller, 1991; Li et al., 1995; Peter et al.,

Abbreviations used in this paper: CDK1, cyclin-dependent kinase 1MPF, Mphase promoting factor.

*Address correspondence to: Jacek Z. Kubiak. Institute of Genetics \& Development, CNRS-UMR 6061, Mitosis and Meiosis Group, IFR140 GFAS, University of Rennes 1, Faculty of Medicine, 2 Ave. Prof. Léon Bernard, CS 34317, 35043 Rennes cedex, France. Fax. +33-2-2323-4478. e-mail: jacek.kubiak@univ-rennes1.fr 
A

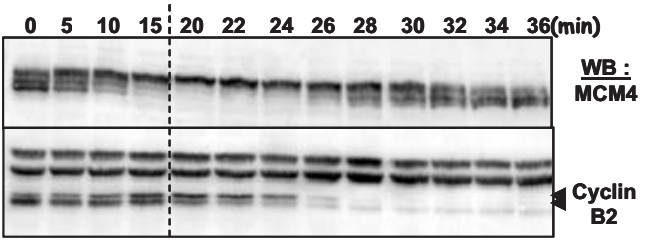

B
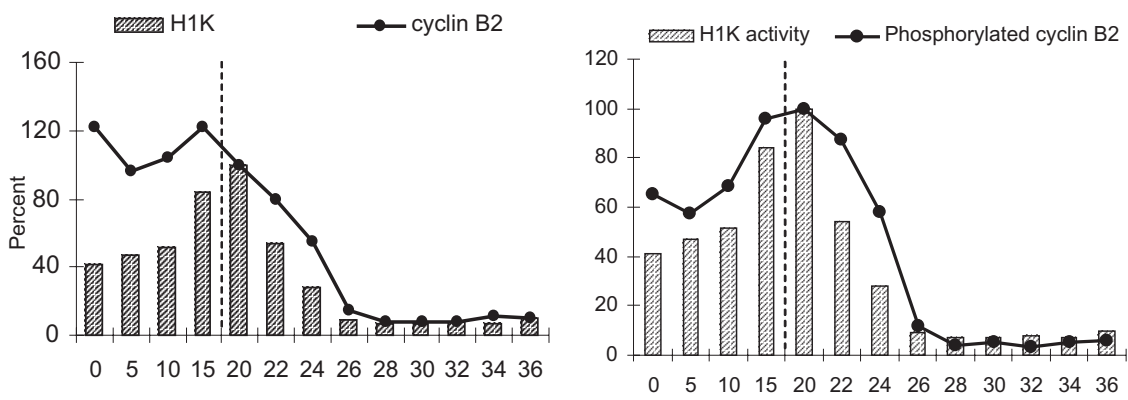

C
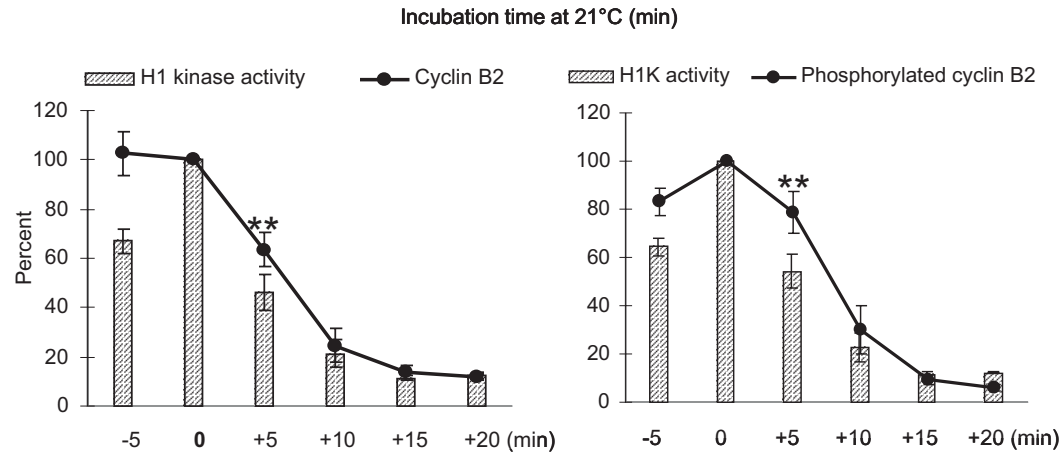

$n=10$

Fig. 1. The dynamics of histone $\mathrm{H} 1$ kinase inactivation are faster than cyclin B2 degradation in cell-free mitotic extract. Samples were collected every 5 min (left from the vertical dotted line) and every 2 min starting from 20 min time point of incubation of the extract at $21^{\circ} \mathrm{C}$ (right from the dotted line). Western blots of MCM4 and cyclin B2 (A) during the first mitosis in cell-free extract are shown. The relationship between histone H1 kinase inactivation (histograms) and the dynamics of total cyclin B2 degradation and the phosphorylated form of cyclin B2 (B) were quantified and plotted. Note that cyclin B2 levels (total and phosphorylated) fall down clearly slower than histone $\mathrm{H} 1$ kinase inactivation at 22 and 24 min time points. Relationship between the dynamics of histone $\mathrm{H} 1$ kinase inactivation and the total pool of cyclin B2 degradation and the phosphorylated form of cyclin B2 (C) in 10 separate experiments. The maximum amplitude of histone $\mathrm{H} 1$ kinase activity, as well as the corresponding value of the quantity of cyclin B2 obtained by quantification of 10 Western blots, were taken as $100 \%$ in each M-phase. Histone H1 kinase values are presented as histograms, while those of cyclin $B 2$ amount as curves. Note that at +5 min time points $(B$, left and right) the values of the means for histone $\mathrm{H} 1$ kinase and cyclin B2 amount are statistically different ${ }^{* *}, p<0.01$; paired t-test).

2002). Due to a clear up-shift on Western blot one can easily distinguish the phosphorylated, certainly associated with CDK1 and non-phosphorylated, not necessarily associated with CDK1 forms of this cyclin B. Cyclin B2 is phosphorylated by different kinases (Mos, Roy et al., 1990; cyk, Stevens et al., 1999; Plk1, Toyoshima-Morimoto et al., 2001; MAP kinase, Walsh et al., 2003) including CDK1 itself (Izumi and Maller, 1991). Judging by a very high affinity of cyclins $B$ to CDK1 and the excess of CDK1 in relation to B-type cyclins in Xenopus laevis oocytes and embryos, the pool of continuously synthesized cyclins most likely forms a complex with CDK1 almost immediately (Kobayashi et al., 1999; Hochegger et al., 2001). Therefore, we suppose that the non-shifted form of cyclin B2 cannot be unequivocally considered as CDK1free, while the shifted one is with no doubt associated with this kinase and forms active MPF (ibid.).

Proteasome inhibition using ALLN or MG132 arrests eukaryotic somatic cells in the mitotic M-phase (Sherwood et al., 1993; Genschik et al., 1998; Uzbekov et al., 1998; Kim et al., 2004). This arrest was attributed to the presence of non-degraded cyclins $B$ (Potapova et al., 2006). However, Nishiyama and colleagues (2000) and our laboratory (Chesnel et al., 2006) observed that MPF inactivation is separated from cyclin B degradation upon meiotic as well as mitotic exit in Xenopus laevis cell-free extracts due to a non-proteolytic activity of the proteasomes themselves. Therefore, inactivation of MPF upon inhibition of the proteasome proteolytic activity apparently requires only the physical separation of cyclin B and CDK1 most likely mediated by the proteasome lid and not by cyclin B degradation (Nishiyama et al., 2000). Moreover, we have shown recently that such a sequence of events takes place also during the exit from the first embryonic M-phase in Xenopus extract without proteasome inhibition (Chesnel et al., 2006). It is therefore likely that the mitotic arrest of somatic cells by proteasome inhibitors is rather due to the presence of other non-degraded substrates which act up stream from cyclins B proteolysis (Chesnel et al., 2006; reviewed by Fry and Yamano, 2006).

Activity of CDK1 depends also on status of its phosphorylation. Phosphorylation of threonine 161 (Thr-160 in CDK2) located in the protein T-loop is absolutely required for its activity (Solomon et al., 1992; De Smedt et al., 2002). Despite that the major kinase phosphorylating CDK1 on this amino acid remains constitutively active during the cell cycle (Shuttleworth et al., 1990) the levels of Thr161 phosphorylation changes between interphase and M-phase (Solomon et al., 1992) suggesting the major regulatory function of some phosphatases. Type 2C protein phosphatases (PP2Cs) were identified as major CDK1 Thr-161 dephosphorylating enzymes in yeast (Cheng et al., 1999) and in Xenopus (De Smedt et al., 2002). Besides this activating phosphorylation, two other residues, namely Thr-14 and Tyr-15, are subjected to the inhibitory phosphorylation within the CDK1 ATP accepting binding site (Krek and Nigg, 1991; Solomon et al., 1992; Rime et al., 1995). This phosphorylation enables to keep CDK1 in its inactive state. Dephosphorylation of Thr-14 and Tyr-15 is therefore necessary 
for CDK1 activation. In Xenopus cell-free extract it precedes slightly the peak of mitotic MPF activation (Chesnel et al., 2005). However, it does not seem to play a crucial role during mitotic inactivation of MPF since rephosphorylation of these two sites is a very slow process and concerns only a small proportion of CDK1 following the first embryonic M-phase (ibid.). Therefore, of these two regulatory mechanisms, only Thr-161 phosphorylation seems a potential key M-phase regulator of CDK1 activity.

Here we focus our attention on interactions between cyclin $\mathrm{B} 2$ and CDK1 in relation to the dynamics of MPF inactivation and Thr-161 phosphorylation status during mitotic exit in Xenopus embryo cell-free extracts. Our data herein confirm that dissociation of cyclin B2 from CDK1 and not cyclin B degradation or Thr-161 dephosphorylation of CDK1 is the earliest event in mitotic MPF inactivation.

\section{Results}

\section{Histone H1 kinase activity declines faster than cyclin B2 amount upon mitotic exit}

During mitosis in cell-free extract cyclin B2 changes its phosphorylation status, as visualised by the up-shift on Western blot and is degraded upon mitotic exit (Fig. 1A, lower blot). Phosphorylation of other proteins, e.g. MCM4 (Fig. 1A, upper blot) which is a direct substrate of CDK1-cyclin B kinase, also changes accordingly to histone $\mathrm{H} 1$ kinase fluctuations which reflects the activity of this kinase (Fig. 1B, histograms).

We compared precisely the dynamics of cyclin B2 diminution and histone $\mathrm{H} 1$ kinase activity. Samples were collected every 5 min at the beginning of the experiment and every 2 min starting from $20 \mathrm{~min}$. incubation time, i.e. the time point when we expected the beginning of the mitotic exit. The maximum of histone $\mathrm{H} 1$ kinase activity as well as the maximum of cyclin B2 level were arbitrarily expressed as $100 \%$ (Fig. 1 B and C). Inactivation of histone $\mathrm{H} 1$ kinase proceeded with clearly faster dynamics than the diminution of cyclin B2 as shown in a representative experiment (Fig. 1B, left and right). The difference in the two dynamics is the highest at 22 and 24 min time points both for the total pool of cyclin B2 (Fig. 1B, left) or the phosphorylated cyclin B2 form (Fig. 1B, right). This suggested that inactivation of histone $\mathrm{H} 1$ kinase could precede cyclin B2 degradation.

We then compared the dynamics of histone $\mathrm{H} 1$ kinase activity and cyclin B2 diminution in ten separate experiments where samples were collected every $5 \mathrm{~min}$ (Fig. 1C). In all experiments, inactivation of histone $\mathrm{H} 1$ kinase proceeded with faster dynamics than diminution of cyclin B2. In statistical data, this difference is clear at the $5 \mathrm{~min}$ time point following the peaks of both histone $\mathrm{H} 1$ kinase activity and cyclin B2 level (Fig. 1C, left and right, "+5 min”). In all but one individual experiments the decline of histone $\mathrm{H} 1$ kinase activity was deeper at that time point than the decline of cyclin B2 level. This difference was statistically significant $(p<0.01$; paired t-test). In the experiment with inverted values for histone $\mathrm{H} 1$ kinase and cyclin B2 level at that time point, the two processes proceeded with the slowest dynamics of all 10 cases examined. In addition, in this particular experiment during further time points (+10, 15 and 20 min.) histone $\mathrm{H} 1$ kinase decline was faster than the decline of cyclin B2 (data not shown). This strengthened our hypothesis that during the mitotic exit the dynamics of inactivation
$\mathbf{A}$ Incubation time at $21^{\circ} \mathrm{C}(\mathrm{min})$

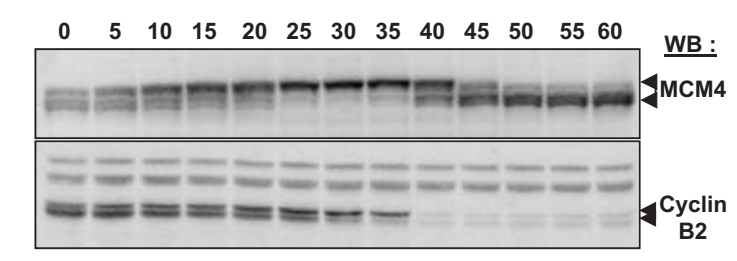

B

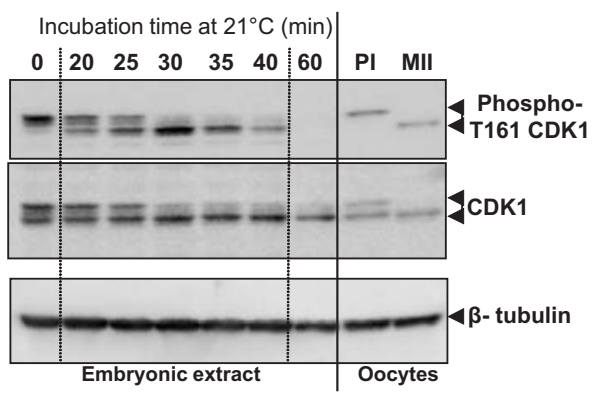

C
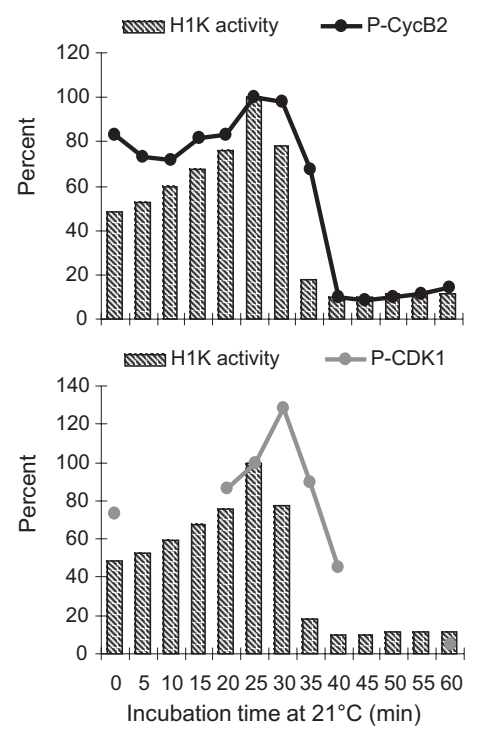

Fig. 2. Dephosphorylation of CDK1 Thr-161 follows MPF inactivation and cyclin B2 degradation in mitotic cell-free extracts. Samples were collected every 5 min during incubation of the low-speed extract at $21^{\circ} \mathrm{C}$ and histone $\mathrm{H} 1$ kinase activity, MCM4, cyclin B2, $\beta$-tubulin (used for quantification as stable standard), total CDK1 and Thr-161-phosphorylated CDK1 levels were examined (A,B). CDK1 and Thr-161 CDK1 levels and migration patterns are also compared between prophase I (PI) and metaphase II (MII) oocytes (B). Histone H1 kinase, phosphorylated cyclin B2 and Thr-161 CDK1 were quantified and their relationship is compared (C). Histone H1 kinase activity decreases the fastest and is followed by cyclin B2 and Thr-161 CDK1 diminution.

of histone $\mathrm{H} 1$ kinase is faster than cyclin $\mathrm{B} 2$ degradation.

\section{Thr-161 dephosphorylation of CDK1 follows histone H1 ki- nase inactivation and cyclin $B 2$ degradation}

Thr-161 dephosphorylation could be involved in inactivation of CDK1 upon mitotic exit. Therefore we studied the dynamics of this process in parallel with histone $\mathrm{H} 1$ kinase activity and cyclin $\mathrm{B} 2$ levels. The comparison of Western blots showing the dynamics of changes of MCM4, cyclin B2, total CDK1 and Thr-161-phospho- 
A

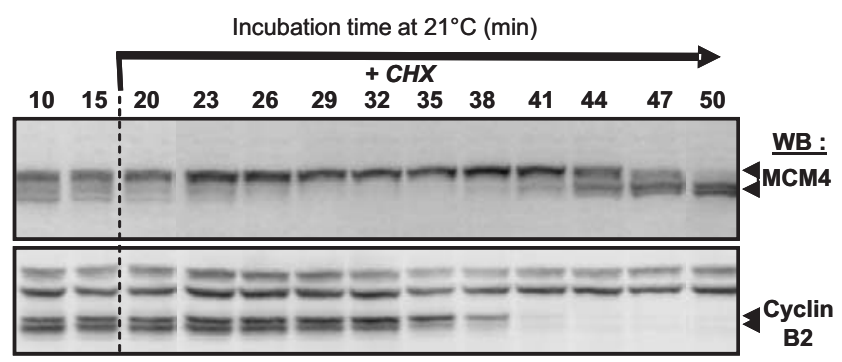

B

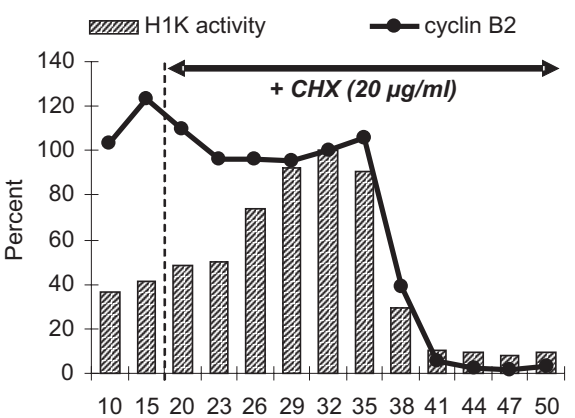

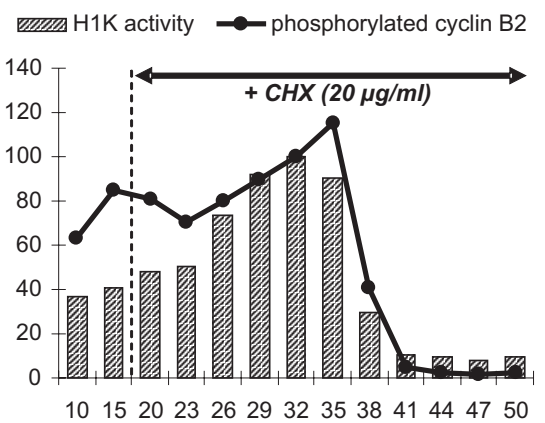

Incubation time at $21^{\circ} \mathrm{C}(\mathrm{min})$

Fig. 3. The dynamics of histone $\mathrm{H} 1$ kinase inactivation is faster than cyclin B2 degradation in the cell-free mitotic extract in which protein synthesis was inhibited with $20 \mu \mathrm{g} / \mathrm{ml}$ CHX 14 min before the peak of histone $\mathrm{H} 1$ kinase activity. Low-speed extracts were incubated at $21^{\circ} \mathrm{C}$ and histone $\mathrm{H} 1$ kinase activity, MCM4 and cyclin B2 levels were examined every 3 min starting from 20 min time point (right from the dotted line). MCM4 and cyclin B2 were blotted (A) and total cyclin B2 and the phosphorylated form of this cyclin were quantified (B). These graphs illustrate the relationship between histone $\mathrm{H} 1$ kinase inactivation and the dynamics of the total pool of cyclin B2 and phosphorylated form of cyclin B2 degradation upon inhibition of protein synthesis. The maximum amplitude of histone $\mathrm{H} 1$ kinase activity observed at 32 min of incubation as well as the level of total and phosphorylated form of cyclin B2 at the same time point obtained by quantification of Western blots were taken as $100 \%$. Histone H1 kinase values are presented as histograms. Note that at 35 and 38 min time points cyclin B2 levels (total or phosphorylated) fall down slower than histone H1 kinase inactivation. rylated CDK1 indicates that the latter is a late mitotic event (Fig. $2 A, B, C$; see the 40 min time point when no trace of cyclin B2 is present while clear levels of Thr-161 CDK1 are detected indicating that it concerns a pool of cyclin-free pool of CDK1). The comparison of quantifications of histone $\mathrm{H} 1$ kinase activity and Western blots shows the differences in these dynamics more clearly (Fig. 2C). Thr-161 phosphorylation increases in parallel with the increase in histone $\mathrm{H} 1$ kinase activity and keeps rising during the very beginning of the drop in this activity. Following the sharp peak of Thr-161 phosphorylation at that time point (30 $\mathrm{min}$ time point in Fig. 2C), it starts to diminish dramatically. The profile of Thr-161 phosphorylation suggests an important regulatory role of this mechanism during M-phase. However, this dephosphorylation occurs too late to be directly involved in inactivation of histone $\mathrm{H} 1$ kinase activity of $\mathrm{CDK} 1$. It seems that it rather prevents precocious re-activation of CDK1 in the absence of rapid and efficient re-phosphorylation of CDK1 on Thr-14 and Tyr-15 (Chesnel et al., 2005).

\section{Newly synthesized cyclin B2 is only partially responsible for the asynchrony between histone $\mathrm{H1}$ kinase inactivation and cyclin B2 diminution during mitotic exit}

The results described so far could be biased by neo-synthesis of cyclin B2 concomitant with its degradation, which would increase the pool of cyclin B2 present during the process of its mitotic degradation. To verify the extent of such a potential bias, we treated cytoplasmic extracts with cycloheximide (CHX; 20 or $50 \mu \mathrm{g} / \mathrm{ml}$ giving the same results) shortly before MPF activity peaks in order to inhibit protein synthesis specifically during the period of MPF inactivation and massive cyclin B degradation (as used before; Chesnel et al., 2005). We analysed the profile of histone $\mathrm{H} 1$ kinase activity as well as cyclin $\mathrm{B} 2$ degradation dynamics (Fig. 3A, lower blot) and MCM4 phosphorylation pattern (Fig. 3A, upper blot) by Western blotting by sampling the extract every $3 \mathrm{~min}$. (starting from $20 \mathrm{~min}$. time point). $\mathrm{CHX}$ was added 18 min. after the beginning of incubation, which corresponded in this experiment to the time point preceding by $14 \mathrm{~min}$ the peak of histone $\mathrm{H} 1$ kinase activity (Fig. 3B). Again, the dynamics of histone $\mathrm{H} 1$ kinase decline was faster than that of diminution of phosphorylated cyclin B2 (compare the curve of cyclin B2 level with the histogram of histone $\mathrm{H} 1$ kinase activity at 35 and $38 \mathrm{~min}$ time points; Fig. 3B, left for the total pool of cyclin B2; right for the phosphorylated forms of cyclin B2). As expected, this difference was smaller than in experiments without CHX (compare with 22 and 24 time points in Fig. 1B), which correlates with the absence of neo-synthesized cyclin B2 upon $\mathrm{CHX}$ treatment. This kind of experiments was repeated at least five times with results confirming this tendency. However, the exact timing (18 min of incubation for $\mathrm{CHX}$ addition) was repeated twice with very similar results despite that in a sibling experiment the period between $\mathrm{CHX}$ addition and histone $\mathrm{H} 1$ kinase peak was $5 \mathrm{~min}$. due to more rapid entry into the M-phase (data not shown). We chose to present here a single representative experiment instead of statistical analysis since in each experiment the maximum of histone $\mathrm{H} 1$ kinase activity took place at slightly different time (after $\mathrm{CHX}$ addition) modifying experimental conditions and making statistics difficult. Indeed, we described recently that cycloheximide modifies both the amplitude and the timing of histone $\mathrm{H} 1$ kinase inactivation in a manner strictly dependent on the period of its action in relation to the beginning of the mitotic exit (see Fig. 6 in Chesnel et al., 2005).

\section{Histone H1 kinase inactivation is synchronised with cyclin B2 separation from CDK1 and not with cyclin B2 degradation}

Since histone $\mathrm{H} 1$ kinase activity strictly depends on the quantity of active CDK1 (associated with cyclin B) we asked whether the asynchrony observed above concerns also cyclin B2 separation from CDK1. To distinguish between the dynamics of diminu- 
tion of the total cyclin B2 pool and the CDK1associated one, we immunoprecipitated proteins present in samples obtained during the experiment similar to the one shown in Fig. 3 (Fig. 4A) collected at 23, 26, 29 and $32 \mathrm{~min}$ of incubation (i.e. before, during and just after the total histone $\mathrm{H} 1$ kinase inactivation and cyclin B2 degradation) with anti-cyclin B2 antibody. Immunoprecipitation was followed by Western blot analysis of the pellet and supernatant with anti-cyclin B2 and anti-CDK1 (Fig. 4B). The cyclin B2 Western blot shows the levels of total cyclin B2 present during the analysed period (Fig. 4B, top panel, "bound"). The CDK1 Western blot shows the levels of CDK1 co-precipitated with this antibody (Fig. 4B, bottom panel, "bound"). The levels of CDK1 visualised in this way are proportional to the levels of cyclin B2 still associated with CDK1 and therefore active as MPF. The Western blots of the pellet were quantified and the dynamics of the total cyclin B2 pool as well as of CDK1 associated with cyclin B2 were compared in parallel with the total activity of histone $\mathrm{H} 1$ kinase measured during the period of MPF inactivation (Fig. 4C, left, top graph for cyclin B2 and left, bottom one for CDK1) and with the total pools of cyclin B2 and CDK1 present in the samples before immunoprecipitation (Fig. 4C, right, top graph for total cyclin B2 and right, bottom one for total CDK1). This shows a clear difference in dynamics between the diminution of the total cyclin B2 level and cyclin B2-associated pool of CDK1 (compare the curves in fig. $4 \mathrm{C}$ left, top graph for cyclin B2 and left, bottom one for cyclin B2associated CDK1). This difference is the most striking at the 26 min time point when cyclin B2 remains still on a high level, while cyclin B2-associated CDK1 has diminished already to $60 \%$ of the maximal level. This shows the clear delay of cyclin B2 degradation in relation to its dissociation from CDK1 during MPF inactivation.

In the same experiment we compared the dynamics in cyclin B2 diminution, CDK1 levels and histone $\mathrm{H} 1$ kinase decline in sibling samples after precipitating CDKs with $\mathrm{p} 9$ beads and visualising CDK1 (Fig. 5A, bottom panel) as well as the co-precipitated cyclin B2 (Fig. 5A, top panel) with Western blot. We reasoned that we should observe relatively stable levels of CDK1 throughout the mitotic exit since $\mathrm{p} 9$ beads do not discriminate between active and inactive CDK1. However, if cyclin B2 indeed dissociates from CDK1 before its degradation, as suggested by the results shown in Fig. 4, we should observe faster histone $\mathrm{H} 1$ kinase inactivation than cyclin B2 diminution as in experiments shown in Fig. 1 and 2 and faster diminution of CDK1-associated cyclin B2 than the diminution of cyclin B2 found in the total pool.

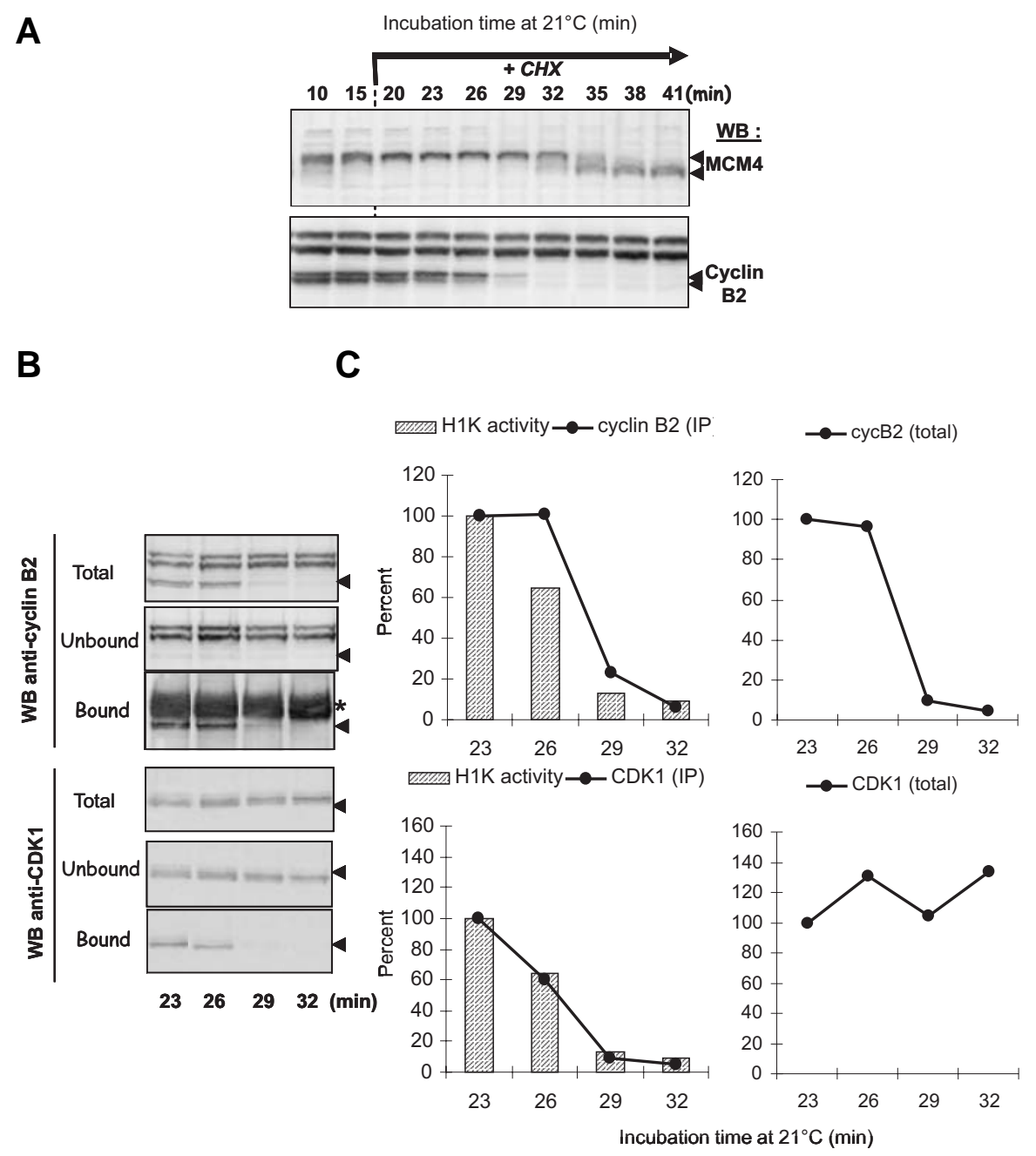

Fig. 4. CDK1 separates from cyclin B2 with faster dynamics than the progression of the proteolysis of this cyclin. Samples were collected every 5 min (left from the vertical dotted line) and every 3 min starting from 20 min time point of incubation of the extract at $21^{\circ} \mathrm{C}$ (right from the dotted line). Western blots of MCM4 and cyclin B2 upon mitotic exit during the first mitosis in cell-free extract are shown (A). Samples from 23, 26, 29 and 32 min of incubation from this experiment (similar to the one shown in Fig. 3) were divided in two equal parts and either immunoprecipitated with anti-cyclin B2 antibody (Fig. 4B) or precipitated with p9 beads (Fig. 5). Total extract, unbound and bound materials were blotted with anti-cyclin B2 and anti-CDK1 (B).

*, IgG heavy chain. Specific signals for the total pool of cyclin B2 and CDK1 (C) present in the same samples of the analysed extract following dilution with IP buffer, but before immunoprecipitation (total) were quantified and plotted. The Western blot of the imunoprecipitaed cyclin B2 was quantified and compared with histone H1 kinase activity. At the 26 min time point, the level of immunoprecipitated cyclin B2 is still high, while the decrease of CDK1 co-precipitated with this cyclin reaches already $60 \%$ of the initial $(23$ min time point) amount of CDK1 coprecipitated with cyclin B2. Note that the dynamics of the decrease in CDK1 associated with immunoprecipitated cyclin B2 is proportional to the decrease in total histone $\mathrm{H} 1$ kinase activity measured during mitotic exit.

Quantifications of Western blots shown in fig. 5A confirmed this hypothesis. CDK1 levels found on $p 9$ beads oscillate slightly (Fig. $5 \mathrm{~B}$, left, bottom), but the total pool of CDK1 present during this period in the collected samples undergoes very similar oscillations (Fig. 5B, right, bottom). Cyclin B2 associated with CDK1 starts to decline slightly at the 26 min. time point (Fig. 5B, left, top, arrow), while histone $\mathrm{H} 1$ kinase activity diminishes already to 60 $\%$ of the maximum and no sign of the decline of the total pool of 
cyclin B2 can be detected at that time point (Fig. 5B, right, top, arrow). Three minutes later CDK1-associated and total cyclin B2 become very low, as well as the histone $\mathrm{H} 1$ kinase activity (Fig. $5 \mathrm{~B}$, top left and right graph respectively). This experiment was repeated twice with very similar results. The experiments shown in Figs. 4 and 5 confirm that the dynamics of cyclin B2 dissociation from CDK1 is slower than histone $\mathrm{H} 1$ kinase inactivation and shows directly that the latter corresponds to the dynamics of CDK1 inactivation and not to cyclin B2 degradation.

\section{Discussion}

In this study, we have investigated the relationship between the dynamics of inactivation of the global MPF activity (reflected by histone $\mathrm{H} 1$ kinase) and the timing of diminution of either the total pool or phosphorylated form of cyclin B2 and Thr-161phosphorylated form of CDK1. Our results show a clear asynchrony between the fast MPF inactivation and slower cyclin B2 degradation and CDK1 dephosphorylation on Thr-161 upon mitotic exit during the first embryonic M-phase in cell-free extract.

Thr-161 dephosphorylation appears the latest of herein studied events potentially involved in MPF inactivation. This enabled us to exclude its role in the immediate mechanism of the switch from active to inactive CDK1. Thr-161 dephosphorylation mediated by 2C protein phosphatases (PP2Cs; Cheng et al., 1999; De Smedt et al., 2002) plays certainly an important role in the cell cycle regulation of CDK1. However, it seems to act rather on monomeric CDK1 which is already inactivated. This argues in favour of a key inactivating role of conformational changes in
CDK1 three-dimensional structure occurring upon its dissociation from cyclin B molecule. For these reasons we will focus further attention on the asynchrony between the MPF inactivation and cyclin B2 association with CDK1 and degradation.

This asynchrony is measurable both in individual as well as in statistically analysed group of such experiments. The newly synthesized, thus yet potentially free of CDK1, cyclin B is only partially responsible for this phenomenon since $\mathrm{CHX}$ treatment only diminishes, but not suppresses, the asynchrony. In addition, p9 precipitation experiments enabling to visualise the dynamics of association/dissociation of cyclin B2 from CDK1 also confirmed the above observations as well as they showed that CDK1associated cyclin B2 starts to diminish before the total pool of cyclin B2. The latter difference suggests the presence in the total pool of cyclin B2 of a portion of this cyclin corresponding to cyclin B2 dissociated from CDK1 and not yet degraded. Immunoprecipitation experiments with anti-cyclin B2 confirmed directly the asynchrony between cyclin B2 separation from CDK1 and its degradation. The separation of CDK1 from cyclin B2 is therefore indeed faster than the proteolysis of this cyclin B upon mitotic inactivation of MPF. The differences in dynamics of biochemical events described in this paper are very subtle and their study required very precise and frequent sampling during mitotic exit. This seems, however, not surprising since we followed here extremely rapid processes. The present data strengthen our hypothesis formulated also in regard to cyclins B1 and B4 (Chesnel et al., 2006) that the dissociation of B-type cyclins from CDK1 and not their degradation per se is responsible for MPF inactivation during mitotic exit in Xenopus embryo cell-free extract.

B
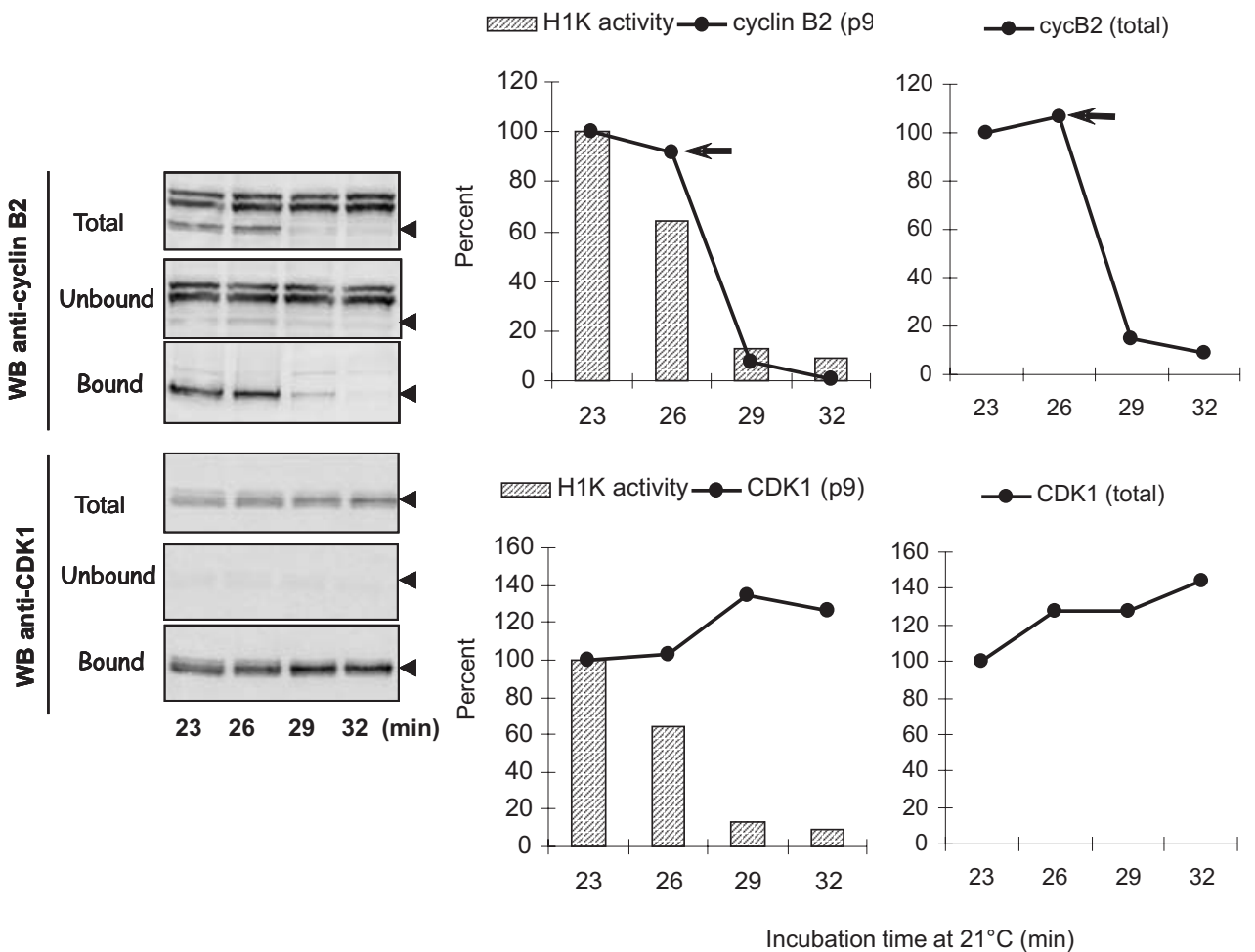

Fig. 5. CDK1-associated cyclin B2 begins to decrease before the diminution of the total pool of this cyclin and its diminution progresses with slower dynamics than inactivation of histone $\mathbf{H 1}$ kinase. Half of the each sample $(23,26,29$ and 32 min of incubation) from the experiment shown in Fig. 4 was precipitated with $p 9$ beads (which have affinity for CDKs) and blotted with anti-cyclin B2 and anti-CDK1 antibodies (A). Total extract, unbound and bound materials were blotted with anti-cyclin B2 and with anti-CDK1. Specific signals for the total pool of cyclin $B 2$ and CDK1 present in the same samples following dilution with IP buffer, but before precipitation (B) (total) were quantified and plotted. The Western blot of the cyclin B2 co-precipitated with CDK1 was quantified and compared with histone $\mathrm{H} 1$ kinase activity. At the 26 min time point the level of co-precipitated cyclin B2 begins to fall down while the total cyclin B2 is still high. p9-bead associated cyclin B2 at that time point falls however with slower dynamics than histone H1 kinase activity similarly as in Figs. 1,3 concerning the whole pool of cyclin B2. The quantities of CDK1 precipitated with p9 beads vary slightly similarly to the total pool of CDK1. 
Cyclin B2 is a particularly interesting example of B-type cyclins metabolism. It is a major cyclin B present in early Xenopus laevis embryos. Its active and phosphorylated form associated with CDK1 is easily distinguishable in Western blots (contrary to cyclin $B 1$ ). It is also one of the latest cyclins B degraded upon mitotic exit. Another major, but earlier-degraded B-type cyclin, namely cyclin $\mathrm{B} 1$, is present in two isoforms also migrating in PAGE as a doublet, but its phosphorylation does not change the mobility in SDS-PAGE (Hochegger et al., 2001). We took the advantages of cyclin B2 as a model for B-type cyclin metabolism to demonstrate straightforwardly the separation of MPF inactivation and B-type cyclins proteolysis.

Cyclins B degradation was considered for a long time as a key event of MPF inactivation (Evans et al., 1983; Murray et al., 1989; Glotzer et al., 1991). A recent study in which the dynamics of mitotic cyclins degradation and histone $\mathrm{H} 1$ kinase inactivation were compared showed that cyclins (labelled with $\mathrm{S}^{35}$ and precipitated on $\mathrm{p} 13^{\text {suc1 }}$ beads, thus associated with CDK1) degradation preceded histone $\mathrm{H} 1$ kinase inactivation (measured after precipitation with $\mathrm{p} 13^{\text {suc1 }}$ beads; Pomerening et al., 2005; see fig. 1V). However, Nishiyama and colleagues (2000) have shown that upon meiotic exit the MPF inactivation in the presence of proteasome inhibitor MG115 takes place in the absence of cyclin $B$ degradation. Since then, the role of the proteolysis of cyclins B in this process was seriously questioned (Josefsberg et al., 2001; Michel et al., 2001; 2004). Recently, our laboratory has confirmed the results by Nishiyama and colleagues (2000) in mitotic extracts of Xenopus laevis one- and two-cell embryos. We have shown that the dissociation of B-type cyclins from CDK1 is sufficient to trigger CDK1 inactivation also during the early mitotic M-phases in such extracts even in the absence of proteasome inhibitors. The direct evidence for that came from our observation that the total pools of cyclins B1, B2 and B4 diminished slower than the pools of respective cyclins $B$ associated with CDK1 (Chesnel et al., 2006). Our results focused on cyclin B2 presented in the current paper reinforce this hypothesis by the observation showing that CDK1-cyclin B2 complex dissociation is faster than cyclin $\mathrm{B} 2$ degradation. They are in clear contradiction with results by Pomerening and colleagues (2005) quoted above. One can speculate that $\mathrm{p} 13^{\text {suct }}$ beads used to precipitate kinases able to phosphorylate histone $\mathrm{H} 1$ by these authors have unspecific affinity to other histone $\mathrm{H} 1$ kinases than $\mathrm{CDK} 1$ which are inactivated following cyclins $B$ degradation. ERK2 MAP kinase is a potential candidate for such a contamination since it binds to p13 ${ }^{\text {suc1 }}$ beads (Shibuya et al., 1992) and is indeed inactivated lately during the first mitosis (Guadagno and Ferrell, 1998; Chesnel et al., 2005).

While inhibition of degradation of endogenous cyclin B does not prevent M-phase exit (Nishiyama et al., 2000; Chesnel et al., 2006, this paper), N-terminal mutants of these cyclins deprived of their degradation boxes (Murray et al., 1989) or N-terminal fragments of cyclins B (Van der Velden and Lohka, 1993) efficiently arrest MPF at the high level. This may appear as a paradox. However, Nishiyama and colleagues (2000) have shown that endogenous cyclin $B$ is sequestered within the proteasome in the CSF extract and our results confirmed this in mitotic extracts (Chesnel et al., 2006), which explains why this cyclin B pool is mitotically inert. On the other hand, Holloway and colleagues (1993) have demonstrated basic differences in the way of action of N-terminal mutants and N-terminal fragments of cyclin B. Namely, the first ones participate in formation of their own MPF activity via association with endogenous CDK1 since degradation box deprived, they are not recognized by the ubiquitin-proteasome pathway. They do not prevent endogenous cyclins proteolysis and substitute for the endogenous pool of cyclins, therefore sister chromatid separation occurs without M-phase exit as degradation of other proteasome substrates is not affected. N-terminal fragments possessing degradation box sequences are recognized by the ubiquitin-proteasome pathway, they act as specific competitors for cyclin degradation, induce a delay both in MPF inactivation as well as in sister chromatids separation (Holloway et al., 1993). Therefore, differential action of each of these cyclins in Xenopus cell-free extracts is comprehensive.

Separation of cyclin B2 from CDK1 before degradation of the cyclin component is not surprising in the light of well documented data concerning a similar fate of other partners present within MPF complex, namely the CDK1 inhibitors (Schwob et al., 1994; Verma et al., 1997). Hence, the proteasome has apparently a capacity to degrade individual proteins and not the proteinous complexes.

In this paper we do not question the major role of cyclins $B$ and specially cyclin B2, degradation for the normal course of the cell cycle. It should be, however, taken into account that the proteolytic degradation of these proteins is relatively late phenomenon of the mitotic exit and in any way it does not participate in MPF inactivation per se contrary to widely accepted model that cyclins $\mathrm{B}$ degradation triggers this process.

\section{Material and Methods}

\section{Frogs and drugs}

Xenopus laevis females were purchased from NASCO (Fort Atkinson, WI, USA). Cycloheximide ( $\mathrm{CHX}$ ) was purchased from Sigma (Irvine, CA, USA). Other chemicals were obtained either from Sigma or ICN (Irvine, CA, USA) unless otherwise stated.

\section{Eggs collection and activation}

Females were subcutaneously injected with human chorionic gonadotropin (500-600 IU per female; Organon, Puteaux, France) and kept overnight at $21^{\circ} \mathrm{C}$ in $110 \mathrm{mM} \mathrm{NaCl}$. Unfertilized eggs collected from "overnight lay" were dejellied with $2 \%$ L-cysteine $\mathrm{pH} 7.81$ in XB buffer (Murray, 1991; $100 \mathrm{mM} \mathrm{KCl}, 1 \mathrm{mM} \mathrm{MgCl}, 50 \mu \mathrm{M} \mathrm{CaCl}_{2}, 10 \mathrm{mM} \mathrm{HEPES}$, $50 \mathrm{mM}$ sucrose $\mathrm{pH} 7.6$ ), washed in $\mathrm{XB}$, treated for 1.5 minute with $0.5 \mu \mathrm{g} /$ $\mathrm{ml}$ calcium ionophore $\mathrm{A} 23187$ and then extensively washed in XB. Eggs were then incubated in $\mathrm{XB}$ at $21^{\circ} \mathrm{C}$.

\section{Cell-free extracts}

Cytoplasmic extracts from calcium ionophore-activated embryos before the first embryonic mitosis were prepared according to Murray (1991) with modifications previously described in Chesnel et al. (2005). These low-speed supernatants were then re-incubated at $21^{\circ} \mathrm{C}$ for 60 min and every $5 \mathrm{~min}$, aliquots were taken out and either frozen in liquid nitrogen and stored at $-70^{\circ} \mathrm{C}$ (for subsequent $\mathrm{H} 1$ kinase activity assays or protein (immuno-precipitations) or mixed with Laemmli sample buffer (Laemmli et al., 1970), heated at $85^{\circ} \mathrm{C}$ for 5 minutes and stored at $-20^{\circ} \mathrm{C}$ (for Western blot analyses).

\section{Electrophoresis, antibodies and Western blotting}

Extracts were subjected to electrophoresis on 8 to $12.5 \%$ SDS-PAGE gels (Laemmli et al., 1970). Separated proteins were transferred to nitrocellulose membranes (Hybond C, Amersham Biosciences) accord- 
ing to standard procedures and probed either with antibodies against cyclin B2 (gift from Thierry Lorca), MCM4 (gift from Marcel Méchali), CDK1 (gift from Tim Hunt), CDK1 Thr-161 (Cell Signalling Technology, gift from Robert Poulhe) and $\beta$-tubuline (Sigma). Antigen-antibody complexes were revealed using alkaline phosphatase conjugated anti-rabbit or anti-mouse secondary antibody (diluted 1:20,000) in combination with Enhanced Chemifluorescence reagent (ECF; Amersham Biosciences). Signal quantification was performed using ImageQuant 5.2 software (Amersham Biosciences).

\section{In vitro assay for histone $\mathrm{H} 1$ kinase activity}

MPF activity in embryos or in cell-free extracts was measured as previously described (Chesnel et al., 1997) with minor modifications: extracts $(1 \mu \mathrm{l})$ were diluted in $25 \mu \mathrm{l}$ MPF buffer $(80 \mathrm{mM} \beta$-glycerophosphate, $50 \mathrm{mM}$ sodium fluoride, $20 \mathrm{mM}$ EGTA, $15 \mathrm{mM} \mathrm{MgCl}_{2}, 1 \mathrm{mM}$ DTT, $20 \mathrm{mM}$ HEPES, pH 7.4) supplemented with $0.5 \mathrm{mM}$ sodium orthovanadate and 5 $\mu \mathrm{g} / \mu \mathrm{l}$ of leupeptin, aprotinin, pepstatin and chymostatin and containing 0.4 $\mathrm{mg} / \mathrm{ml} \mathrm{H} 1$ histone (type III-S), $1 \mu \mathrm{Ci}\left[\gamma^{32} \mathrm{P}\right]$ ATP (specific activity: $3000 \mathrm{Ci} /$ mmol; Amersham Biosciences) and $0.8 \mathrm{mM} \mathrm{ATP.} \mathrm{After} \mathrm{incubation} \mathrm{for} 30$ minutes at $30^{\circ} \mathrm{C}$, phosphorylation reactions were stopped by adding Laemmli sample buffer and heating for 5 minutes at $85^{\circ} \mathrm{C}$. Histone $\mathrm{H} 1$ was separated by SDS-PAGE and incorporated radioactivity was measured by autoradiography of the gel using a STORM phosphorimager (Amersham Biosciences) followed by a data analysis with ImageQuant 5.2 software.

\section{Cyclin B2 immunoprecipitation}

For immunoprecipitation, $10 \mu \mathrm{l}$ of extracts were diluted 20 times in IP buffer (20mM Tris-HCl pH 7.5, $150 \mathrm{mM} \mathrm{NaCl}, 50 \mathrm{mM} \beta$-glycerophosphate, $50 \mathrm{mM}$ sodium fluoride, $2 \mathrm{mM}$ EDTA, 10\% glycerol, $0.2 \%$ nonidet-P40) extemporaneously supplemented with $0.5 \mathrm{mM} \mathrm{AEBSF}$, aprotinin, leupeptin, pepstatin $(5 \mu \mathrm{g} / \mathrm{ml}$ each) and $0,5 \mathrm{mM}$ sodium orthovanadate. A $5 \mu$-aliquot of this diluted extract ("total") was collected to be analyzed by Western blotting and purified anti-cyclin B antibody was added to the extract. After a $1 \mathrm{hr}$-incubation on ice, $10 \mu \mathrm{l}$ protein A Affiprep beads (Bio-Rad) preequilibrated in IP buffer were added and the mixture was agitated for $12 \mathrm{~h}$ at $4^{\circ} \mathrm{C}$. After centrifugation $\left(1,000 \mathrm{~g}, 3 \mathrm{~min}, 4^{\circ} \mathrm{C}\right.$ ), the supernatant ("unbound") was collected to be analyzed by Western blotting while the pelleted beads were washed four times with $1 \mathrm{ml}$ of IP buffer and once with $20 \mathrm{mM}$ Tris- $\mathrm{HCl} \mathrm{pH} \mathrm{7.5;} 150 \mathrm{mM} \mathrm{NaCl}$. The beads were then resuspended in $10 \mu \mathrm{l}$ of $2 x$ Laemmli sample buffer and heated at $85^{\circ} \mathrm{C}$ for $5 \mathrm{~min}$. Samples ("total", "unbound" and "bound") were then subjected to 12\% SDS-PAGE and cyclin $\mathrm{B}$ and CDK1 were detected by Western blotting.

\section{CDK1 precipitation with $p 9$ beads}

The $p 9$ sepharose beads used for affinity precipitation were kindly provided by Lénaïck Detivaud and Laurent Meijer (Roscoff). Ten $\mu$ l of extracts were added to $10 \mu \mathrm{lp} 9$ beads pre-equilibrated with homogeneizing buffer (MOPS pH 7.2, 60 mM $\beta$-glycerophosphate, 15 mM EGTA, 15 mM $\mathrm{MgCl}_{2}, 2 \mathrm{mM}$ dithiothreitol, $1 \mathrm{mM}$ sodium fluoride, $1 \mathrm{mM}$ sodium orthovanadate and $1 \mathrm{mM}$ disodium phenyl phosphate) extemporaneously supplemented with $1 \%$ BSA, $1 \mathrm{mM}$ AEBSF and aprotinin, leupeptin, pepstatin, chymostatin $\left(10 \mu \mathrm{g} / \mathrm{ml}\right.$ each). The mixtures were agitated for $2.5 \mathrm{~h}$ at $4^{\circ} \mathrm{C}$. After a brief centrifugation $\left(5,000 \mathrm{~g}, 1 \mathrm{~min}, 4^{\circ} \mathrm{C}\right)$, the supernatant (" $u$ bound") was collected to be analyzed by Western blotting while the pelleted p9 beads ("bound") were washed four times with $1 \mathrm{ml}$ of washing buffer (50 mM Tris- $\mathrm{HCl} \mathrm{pH} \mathrm{7.4,250} \mathrm{mM} \mathrm{NaCl,} 5$ mM EDTA, 5 mM EGTA, $5 \mathrm{mM}$ sodium fluoride and $0.1 \%$ nonidet-P 40 ) containing $0.5 \mathrm{mM} \mathrm{AEBSF}$, aprotinin, leupeptin, pepstatin, chymostatin $(10 \mu \mathrm{g} / \mathrm{ml}$ each). The beads were then resuspended in $12 \mu \mathrm{l}$ of $2 \mathrm{x}$ Laemmli sample buffer and heated at $85^{\circ} \mathrm{C}$ for 5 min. Samples ("total", "unbound" and "bound") were then subjected to $12 \%$ SDS-PAGE and cyclin B and CDK1 were detected by Western blotting.

\section{Statistics}

The relationship between activity of histone $\mathrm{H} 1$ kinase and the level of cyclin B2 was analysed using paired t-test (http://faculty.vassar.edu/ lowry/VassarStats.htm).

\section{Acknowledgements}

We thank Marcel Méchali, Tim Hunt, Thierry Lorca and Robert Poulhe for generous gifts of antibodies, Lénaïck Detivaud and Laurent Meijer for p9 beads and Zbigniew Polanski for his help in statistical analysis. We thank Laurent Richard-Parpaillon, Anna Castro, Thierry Lorca and Jacek Gaertig for valuable discussions. This work was supported by grants from ARC (4298), Ligue Contre le Cancer (Comité d'llle-et-Vilaine) and BQR (Université Rennes 1) to J.Z.K.

\section{References}

CHENG A, ROSS KE, KALDIS P, SOLOMON MJ. (1999). Dephosphorylation of cyclin-dependent kinases by type 2C protein phosphatases. Genes Dev. 13; 2946-57.

CHESNEL F, BONNEC G, TARDIVEL A, BOUJARD D. (1997). Comparative effects of insulin on the activation of the Raf/Mos-dependent MAP kinase cascade in vitellogenic versus postvitellogenic Xenopus oocytes. Dev Biol. 188: 122-33.

CHESNEL F, VIGNAUX F, RICHARD-PARPAILLON L, HUGUET A, KUBIAK JZ. (2005). Differences in regulation of the first two M-phases in Xenopus laevis embryo cell-free extracts. Dev Biol. 285: 358-75.

CHESNEL F, BAZILE F, PASCAL A, KUBIAK JZ. (2006). Cyclin B dissociation from CDK1 precedes its degradation upon MPF inactivation in mitotic extracts of Xenopus laevis embryos. Cell Cycle 5: 1687-98.

CIECHANOVER A. (2005). Proteolysis: from the lysosome to ubiquitin and the proteasome. Nature Rev Molec Cell Biol. 6: 79-87.

DE SMEDT V, POULHE R, CAYLA X, DESSAUGE F, KARAISKOU A, JESSUS C, OZON, R. (2002). Thr-161 phosphorylation of monomeric Cdc2. Regulation by protein phosphatase 2C in Xenopus oocytes. J Biol Chem. 277: 28592-600.

EVANS T, ROSENTHAL ET, YOUNGBLOM J, DISTEL D, HUNT T. (1983). Cyclin: a protein specified by maternal mRNA in sea urchin eggs that is destroyed at each cleavage division. Cell 33: 389-96.

FRY AM, YAMANO H. (2006). APC/C-Mediated Degradation in Early Mitosis: How to Avoid Spindle Assembly Checkpoint Inhibition. Cell Cycle 5: 1487-91.

GAUTIER J, MALLER JL. (1991). Cyclin B in Xenopus oocytes: implications for the mechanism of pre-MPF activation. EMBO J. 10: 177-82.

GENSCHIK P, CRIQUI MC, PARMENTIER Y, DEREVIER A, FLECK J. (1998). Cell cycle -dependent proteolysis in plants. Identification Of the destruction box pathway and metaphase arrest produced by the proteasome inhibitor MG132. Plant Cell 10: 2063-76.

GLOTZER M, MURRAY AW, KIRSCHNER MW. (1991). Cyclin is degraded by the ubiquitin pathway. Nature 349: 132-8.

GUADAGNO TM, FERRELL JE JR. (1998). Requirement for MAPK activation for normal mitotic progression in Xenopus egg extracts. Science 282: 1312-5.

HERSHKO A. (2005). The ubiquitin system for protein degradation and some of its roles in the control of the cell division cycle. Cell Death Differ. 12: 1191-7.

HOCHEGGER H, KLOTZBUCHER A, KIRK J, HOWELL M, LE GUELLEC K, FLETCHER K, DUNCAN T, SOHAIL M, HUNT T. (2001). New B-type cyclin synthesis is required between meiosis I and II during Xenopus oocyte maturation. Development 128: 3795-807.

HOLLOWAY SL, GLOTZER M, KING RW, MURRAY AW. (1993). Anaphase is initiated by proteolysis rather than by the inactivation of maturation-promoting factor. Cell 73: 1393-402.

IZUMI T, MALLER JL. (1991). Phosphorylation of Xenopus cyclins B1 and B2 is not required for cell cycle transitions. Mol Cell Biol. 11: 3860-7.

JOSEFSBERG LB, KAUFMAN O, GALIANI D, KOVO M, DEKEL N. (2001). Inactivation of $\mathrm{M}$-phase promoting factor at exit from first embryonic mitosis in the rat is independent of cyclin B1 degradation. Biol Reprod. 64: 871-8.

KIM OH, LIM JH, WOO KJ, KIM YH, JIN IN, HAN ST, PARK JW, KWON TK. (2004). Influence of p53 and p21Waf1 expression on G2/M phase arrest of colorectal carcinoma HCT116 cells to proteasome inhibitors. Int J Oncol. 24: 935-41.

KOBAYASHI H, MINSHULL J, FORD C, GOLSTEYN R, POON R, HUNT T. (1990) 
On the synthesis and destruction of A- and B-type cyclins during oogenesis and meiotic maturation in Xenopus laevis. J Cell Biol. 114: 755-65.

LAEMMLI UK. (1970). Cleavage of structural proteins during the assembly of the head of bacteriophage T4. Nature 227: 680-5.

LI J, MEYER AN, DONOGHUE DJ. (1995). Requirement for phosphorylation of cyclin B1 for Xenopus oocyte maturation. Mol Biol Cell 6: 1111-24.

MEIJER L, ARION D, GOLSTEYN R, PINES J, BRIZUELA L, HUNT T, BEACH†D. (1989). Cyclin is a component of the sea urchin egg M-phase specific histone H1 kinase. EMBO J. 8: 2275-82.

MICHEL LS, LIBERAL V, CHATTERJEE A, KIRCHWEGGER R, PASCHE B, GERALD W, DOBLES M, SORGER PK, MURTY VV, BENEZRA R. (2001). MAD2 haplo-insufficiency causes premature anaphase and chromosome instability in mammalian cells. Nature 409: 355-9.

MICHEL L, DIAZ-RODRIGUEZ E, NARAYAN G, HERNANDO E, MURTY VV, BENEZRA R. (2004). Complete loss of the tumor suppressor MAD2 causes premature cyclin $B$ degradation and mitotic failure in human somatic cells. Proc Natl Acad Sci USA 101: 4459-64.

MURRAY, AW, SOLOMON MJ, KIRSCHNER MW. (1989). The role of cyclin synthesis and degradation in the control of maturation promoting factor activity. Nature 339: 280-6.

MURRAY AW. (1991). Cell cycle extracts. Methods Cell Biol. 36: 581-605.

NISHIYAMA A, TACHIBANA K, IGARASHIY, YASUDA H, TANAHASHIN, TANAKA K, OHSUMI K, KISHIMOTOT. (2000). A nonproteolytic function of the proteasome is required for the dissociation of $\mathrm{Cdc} 2$ and cyclin $\mathrm{B}$ at the end of $\mathrm{M}$ phase. Genes Dev. 14: 2344-57.

PETER M, LE PEUCH C, LABBÉ J-C, MEYER AN, DONOGHUE DJ, DORÉE M. (2002). Initial activation of cyclin-B1-cdc2 kinase requires phosphorylation of cyclin B1. EMBO Rep. 3: 551-6.

PETERS JM. (2002). The anaphase-promoting complex: proteolysis in mitosis and beyond. Mol Cell 9: 931-43.

POMERENING JR, KIM SY, FERRELL JE JR. (2005). Systems-level dissection of the cell-cycle oscillator: bypassing positive feedback produces damped oscillations. Cell 122: 565-78.

POTAPOVA TA, DAUM JR, PITTMAN BD, HUDSON JR, JONES TN, SATINOVER DL, STUKENBERG PT, GORBSKY GJ. (2006). The reversibility of mitotic exit in vertebrate cells. Nature 440: 954-8.

RIME H, JESSUS C, OZON R. (1995). Tyrosine phosphorylation of p34cdc2 is regulated by protein phosphatase $2 \mathrm{~A}$ in growing immature Xenopus oocytes. Exp Cell Res. 219, 29-38.

ROY LM, SINGH B, GAUTIER J, ARLINGHAUS RB, NORDEEN SK, MALLER JL. (1990). The cyclin B2 component of MPF is a substrate for the c-mos ${ }^{\mathrm{xe}}$ proto- oncogene product. Cell 5: 825-31.

SCHWOB E, BÖHM T, MENDENHALL M, NASMYTH K. (1994). The B-type cyclin kinase inhibitor $\mathrm{p} 40^{\mathrm{sic} 1}$ controls the G1/S transition in S. cerevisiae. Cell79: 23344.

SHERWOOD SW, KUNG AL, ROITELMAN J, SIMONI RD, SCHIMKE RT. (1993). In vivo inhibition of cyclin $B$ degradation and induction of cell-cycle arrest in mammalian cells by the neutral cysteine protease inhibitor $\mathrm{N}$ acetylleucylleucylnorleucinal. Proc Natl Acad Sci USA 90: 3353-7.

SHIBUYA EK, BOULTON TG, COBB MH, RUDERMAN JV. (1992). Activation of p42 MAP kinase and the release of oocytes from cell cycle arrest. EMBO J.11: 3963-75.

SHUTTLEWORTH J, GODFREY R, COLMAN A. (1990). p40MO15, a cdc2-related protein kinase involved in negative regulation of meiotic maturation of Xenopus oocytes. EMBO J. 9: 3233-40.

SOLOMON MJ, LEE T, KIRSCHNER MW. (1992). Role of phosphorylation in p34cdc2 activation: identification of an activating kinase. Mol Biol Cell. 3, 13-27.

STEVENS I, DERUA R, RONDELEZ E, WAELKENS E, MERLEVEDE W, GORIS J. (1999). Identification of cyk, a cyclin B2 kinase, as a novel calcium/calmodulindependent protein kinase II and its role during Xenopus laevis oocyte maturation. Exp Cell Res. 252: 303-18.

TOYOSHIMA-MORIMOTO F, TANIGUCHI E, SHINYA N, IWAMATSU A, NISHIDA E. (2001). Polo-like kinase 1 phosphorylates cyclin B1 and targets it to the nucleus during prophase. Nature 410: 215-20.

UZBEKOV R, CHARTRAIN I, PHILIPPE M, ARLOT-BONNEMAINS Y. (1998). Cell cycle analysis and synchronization of the Xenopus cell line XL2. Exp Cell Res 242:60-8.

VAN DER VELDEN HM, LOHKA MJ. (1993). Mitotic arrest caused by the amino terminus of Xenopus cyclin B2. Mol Cell Biol. 13: 1480-8.

VERMA R, ANNAN RS, HUDDLESTON MJ, CARR SA, REYNARD G, DESHAIES RJ. (1997). Phosphorylation of Sic1p by G1 Cdk required for its degradation and entry into S phase. Science 278: 455-60.

WALSH S, MARGOLIS SS, KORNBLUTH S. (2003). Phosphorylation of the Cyclin B1 Cytoplasmic Retention Sequence by Mitogen-Activated Protein Kinase and PIx. Molec. Cancer Res. 1: 280-9.

Received: 14th February 2007 Reviewed by Referees: 14th March 2007

Modified by Authors and Accepted for Publication: 23rd March 2007 Published Online: 17 May 2007 


\section{Related, previously published Int. J. Dev. Biol. articles of interest}

See our Special Issue on Mammalian Reproduction and Development edited by Brigid Hogan at: http://www.ijdb.ehu.es/web/contents.php?vol=45\&issue=3

Drosophila Mrityu encodes a BTB/POZ domain-containing protein and is expressed dynamically during development

Jamie C. Rusconi and Uma Challa

Int. J. Dev. Biol. (2007) 51: 259-263

Accumulation and dynamics of proteins of the MCM family during mouse oogenesis and the first embryonic cell cycle

Lukasz Swiech, Katarzyna Kisiel, Renata Czolowska, Maciej Zientarski and Ewa Borsuk

Int. J. Dev. Biol. (2007) 51: 2239-2239

Where do we stand now? - mouse early embryo patterning meeting in Freiburg, Germany (2005)

Takashi Hiiragi, Vernadeth B. Alarcon, Toshihiko Fujimori, Sophie Louvet-Vallée, Marek Maleszewski, Yusuke Marikawa, Bernard Maro and Davor Solter

Int. J. Dev. Biol. (2006) 50: 581-588

Science is not a democracy

Jacek Z. Kubiak

Int. J. Dev. Biol. (2006) 50: 586

Synchronised cycling gene oscillations in presomitic mesoderm cells require cell-cell contact Miguel Maroto, J. Kim Dale, Mary-Lee Dequéant, Anne-Cécile Petit and Olivier Pourquié Int. J. Dev. Biol. (2005) 49: 309-315

Regulation of cell adhesion and migration in lens development Peggy S. Zelenka

Int. J. Dev. Biol. (2004) 48: 857-865

Mammalian oocyte activation: lessons from the sperm and implications for nuclear transfer. R Alberio, V Zakhartchenko, J Motlik and E Wolf

Int. J. Dev. Biol. (2001) 45: 797-809

p34(cdc2) and mitotic cyclin expression in the developing quail neuroretina.

X Espanel, A Kastner, O Stettler, B Tavitian, G Brun and G Gillet

Int. J. Dev. Biol. (1997) 41: 469-476

Localised MPF activation and mitotic phosphorylation in fertilised Xenopus eggs.

D Pérez Mongiovi, $P$ Chang and E Houliston

Int. J. Dev. Biol. (1996) 40: S219-S220

Cell reproduction: induction of M-phase events by cyclin-dependent cdc2 kinase.

T Kishimoto

Int. J. Dev. Biol. (1994) 38: 185-191

Kinetics of MPF and histone $\mathrm{H} 1$ kinase activity differ during the G2- to M-phase transition in mouse oocytes. T Jung, R M Moor and J Fulka

Int. J. Dev. Biol. (1993) 37: 595-600 


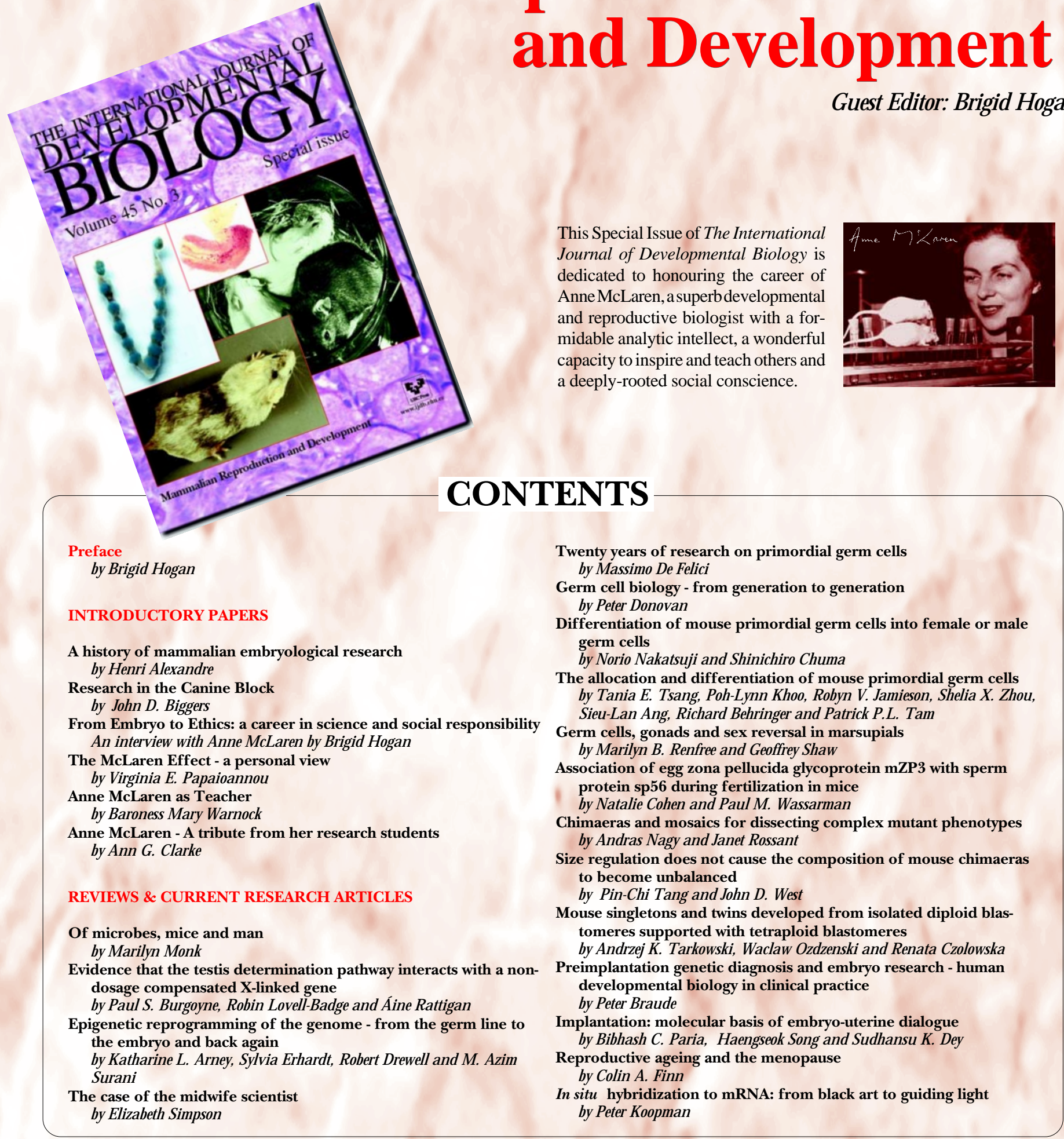

\section{ORDER FORM}

I would like to order ___ cop(y/ies) of the Int. J. Dev. Biol. Special Issue “Mammalian Reproduction and Development” (Vol. 45, № 3) at US\$ 90 or Euro $€ 70$ per copy (including post and packaging). Total to be charged: US\$ / Euro $€$ (please specify currency)

\section{ORDER BY}

$\checkmark$ Web: http://www.intjdevbiol.com

$\checkmark$ E-mail: ijdb@ehu.es (include the information indicated above)

$\checkmark$ FAX: +34-94-601-3266

$\checkmark$ POST: to the address shown beside
The International Journal of Developmental Biology

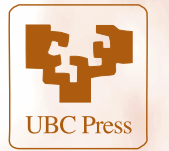

UBC Press - Faculty of Medicine

University of the Basque Country, E-48940 Leioa, Vizcaya,

SPAIN 